\title{
C2-C3 spinal fracture subluxation with ligamentous and vascular injury: a case report and review of management
}

\author{
Hepzibha Alexander ${ }^{1} \cdot$ Ehsan Dowlati $^{1} \cdot$ Jason E. McGowan ${ }^{1} \cdot$ Robert B. Mason ${ }^{2} \cdot$ Amjad Anaizi $^{1}$
}

Received: 4 November 2018 / Revised: 1 January 2019 / Accepted: 2 January 2019

(c) International Spinal Cord Society 2019

\begin{abstract}
Introduction Spinal cord injury is one of the leading causes of paralysis and permanent morbidity. High cervical spine injuries, in particular, have the potential to be fatal and debilitating due to injury to multiple components, including but not limited to, discoligamentous disruption, vascular insult and spinal cord injury. To date, no unifying algorithm exists making it challenging to guide treatment decisions.

Case presentation We present the case of a 29-year-old polytrauma patient with an unstable C2-C3 fracture subluxation secondary to hyperextension and rotation injury with complete ligamentous dissociation and vertebral artery dissection after a high-velocity injury. We review the literature on injury patterns, associated complications and neurological outcomes in subaxial cervical spine injuries.

Discussion Our patient's injuries had several components including fracture subluxation, ligamentous disruption, central cord syndrome, and vascular insult. The lack of a unifying algorithm to guide treatment decisions highlights the variations in pathology and subsequent limitations in generalizability of current literature. Our patient underwent an open anterior C2-C3 reduction and discectomy with fusion and plating and a subsequent $\mathrm{C} 2-\mathrm{C} 4$ posterior instrumented fusion. The patient regained some motor function postoperatively and through rehabilitation. Careful consideration of multiple components is crucial when treating subaxial spine injuries.
\end{abstract}

\section{Introduction}

About 17,500 new spinal cord injury (SCI) cases occur in the United States each year. Full recovery is difficult to achieve, and SCI patients have extremely high lifelong healthcare expenses and a significantly diminished quality of life [1]. Common neurologic deficits include incomplete tetraplegia, incomplete paraplegia, complete paraplegia and complete tetraplegia [2]. Due to these devastating consequences, it is important to have a high threshold of suspicion for SCI, particularly in polytrauma patients with severe maxillofacial injuries. Moreover, one of the most

Ehsan Dowlati

edowlati@gmail.com

1 Department of Neurosurgery, Medstar Georgetown University Hospital, 3800 Reservoir Rd., PHC 7, Washington, DC 20007, USA

2 Department of Neurosurgery, Medstar Washington Hospital Center, 110 Irving St. NW, Washington, DC 20010, USA devastating consequences of cervical spine trauma is injury to the vertebral artery, which can result in a posterior circulation stroke if left untreated. Therefore, it is important to suspect vertebral artery injury in any patient who presents with cervical spine trauma, particularly with fractures and dislocations. Careful monitoring is crucial as patients can initially be asymptomatic or signs and symptoms can be masked by other concomitant injuries [3].

The challenge in treating subaxial spinal cord injuries is the lack of a unifying algorithm to guide treatment decisions. Traumatic SCIs encompass a wide range of pathology across distinct regions of the spinal column, each with unique biomechanical and anatomic profiles. Neurologic status must be considered along with the fracture pattern [4]. Several classification systems have been proposed, however, the validity and practicality of these systems remains unclear. The current recommendation is to use the subaxial injury classification (SLIC) to define the SCI. This system provides a quantitative measure to determine the threshold for surgical intervention [5]. The SLIC score is determined using three indicators of neurologic outcome (1) injury morphology, (2) discoligamentous integrity, and (3) 


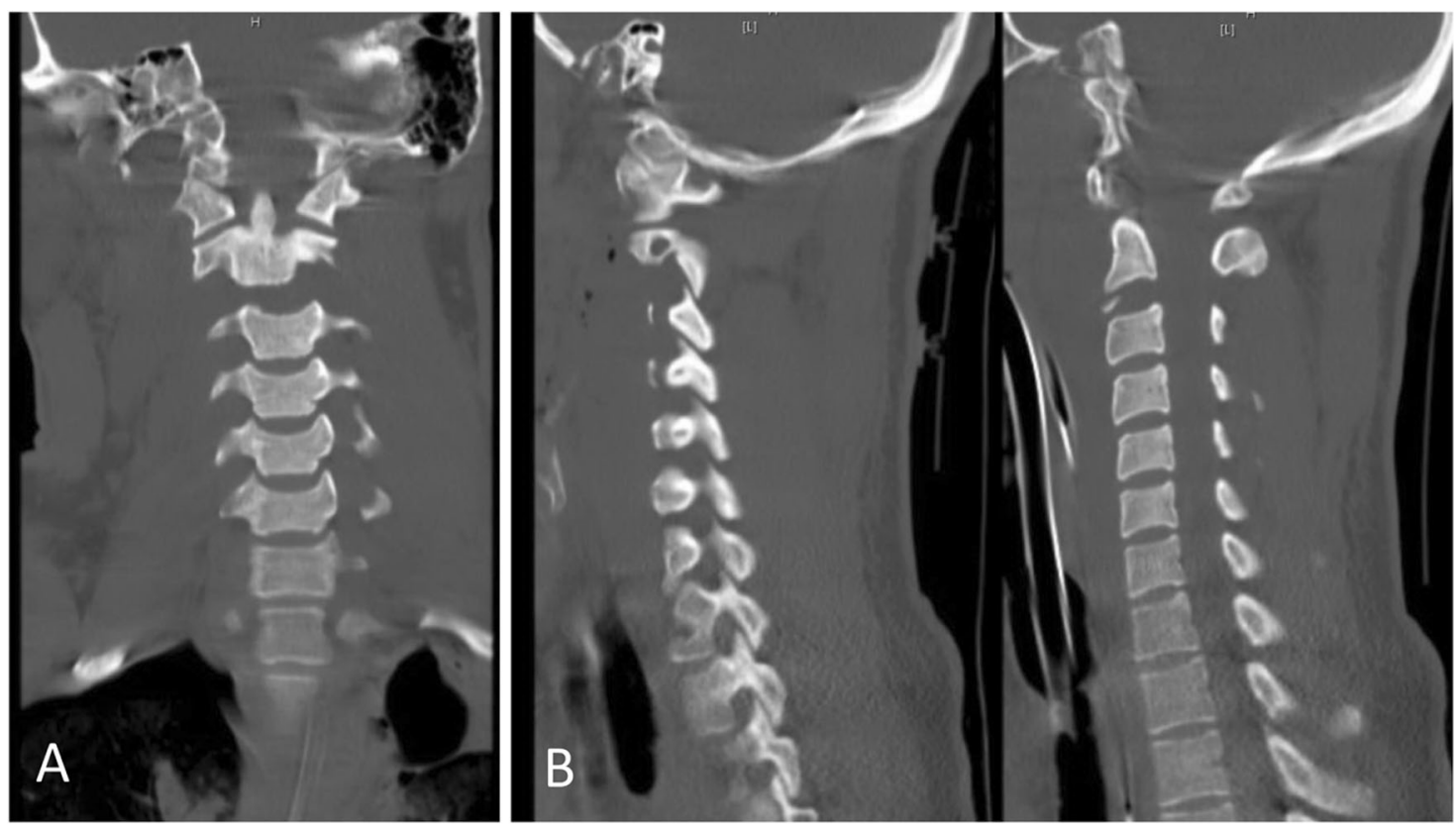

Fig. 1 a Coronal b Sagittal views of cervical spine CT scan showing marked widening of the disc space at C2-C3 and a small avulsion fracture along the anterior inferior aspect of $\mathrm{C} 2$ as well as widening distance of the facet space and spinous processes of C2 and C3

neurologic status. Each category is analyzed individually and scored. A score less than or equal to three indicates conservative management while a score greater than five suggests surgical intervention [6-8]. Early surgery is thought to benefit patients with unstable fractures but there is no consensus on the timing or type of surgery.

We present the case of a 29-year-old polytrauma patient with an unstable $\mathrm{C} 2-\mathrm{C} 3$ fracture subluxation secondary to hyperextension and rotation injury and a review of the literature on injury patterns, associated complications and neurological outcomes in subaxial cervical spine injuries. Consent was obtained from the patient for this case presentation.

\section{Case presentation}

A 29-year-old male was brought into the trauma bay with multiple injuries after he was pinned between two trucks as a pedestrian. Upon arrival, he was unresponsive with a Glasgow Coma Scale (GCS) of 3. Bilateral chest tubes were placed for a right pneumothorax and left hemothorax. He then had pulseless electrical activity necessitating a thoracotomy and pericardiotomy. Upon return of spontaneous circulation, a trauma workup revealed extensive fractures of the face, ribs, femur and pubic ramus. Computed tomography (CT) scan of the cervical spine (Fig. 1) revealed marked widening of the disc space at $\mathrm{C} 2-\mathrm{C} 3$ and a small avulsion fracture along the anterior inferior aspect of $\mathrm{C} 2$. No subluxation was noted on initial CT. No signs of acute intracranial pathology were noted on the head CT. A magnetic resonance imaging (MRI) could not be obtained due to hemodynamic instability.

After stabilization, his GCS improved to 11T. He was on intubated and on mechanical ventilation. He opened his eyes to voice and was following commands. Right lower extremity demonstrated anti-gravity movement in plantarflexion and dorsiflexion and some movement in proximal muscle groups, but not against gravity. His left lower extremity was limited to movement due to a left femur fracture. No motor function was noted in bilateral upper extremities. The patient was classified as C4AIS - C tetraplegia. Exam also revealed grossly intact sensation in all extremities. His bowel and bladder function were intact as noted by rectal tone and absence of saddle anesthesia. A bladder foley catheter was placed to monitor urine output accurately. He was kept in a cervical hard collar and mean arterial pressure was maintained greater than $85 \mathrm{mmHg}$ as per protocol at our institution.

A computed tomography angiography (CTA) of the head and neck (Fig. 2) showed a traumatic occlusion of the left vertebral artery extending from $\mathrm{C} 4$ level to the intradural portion of the left vertebral artery and a non-occlusive dissection of the right vertebral artery at the C2-C3 level. This led to a left posterior inferior cerebellar artery (PICA) infarct. These findings were further confirmed by a cerebral angiogram. Endovascular occlusion of the dissected right vertebral artery was not performed due to concerns for brainstem infarction if the basilar artery did not receive sufficient blood flow through the posterior communicating arteries. Treatment was started with aspirin. 
Fig. 2 Coronal cuts of the CTA of the neck showing occlusion of the left vertebral artery intradural portion and dissection of the right vertebral artery at C2-C3 extending from $\mathrm{C} 4$ level to the

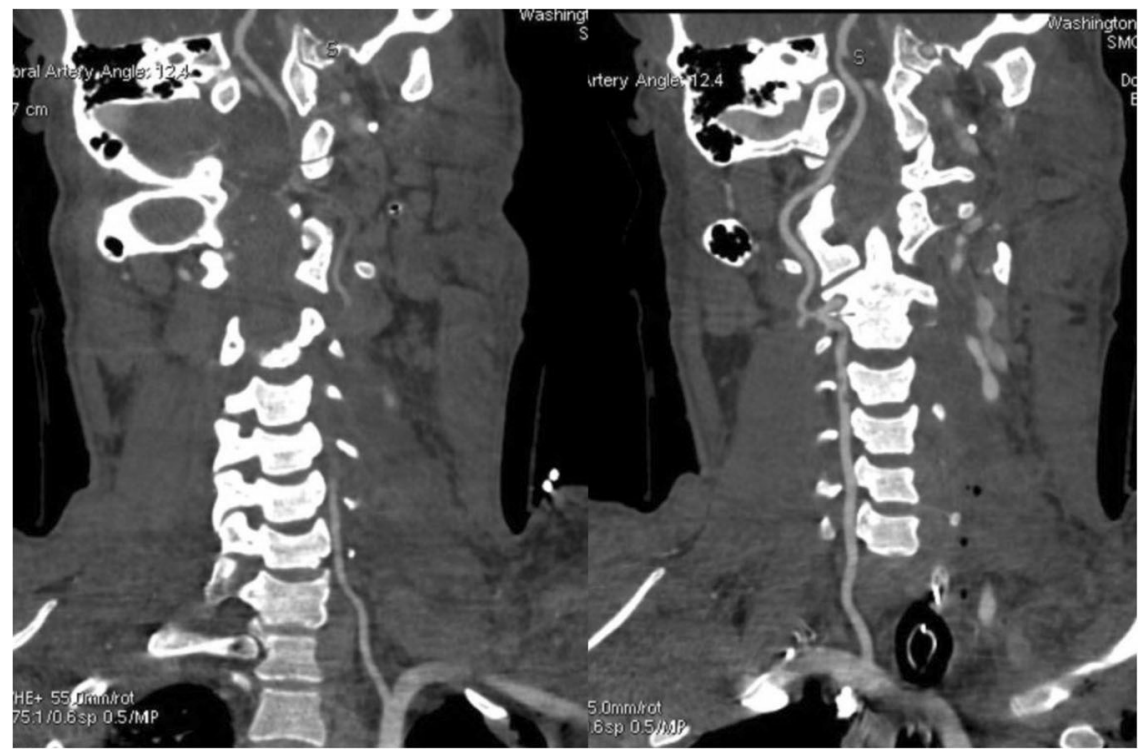

Fig. 3 a T2-weighted and b. STIR MRI images showing complete ligamentous disruption. Fracture subluxation is present at $\mathrm{C} 2-\mathrm{C} 3$ with rupture of the anterior longitudinal ligament, posterior longitudinal ligament, interspinous ligaments and with associated cord edema at $\mathrm{C} 3$

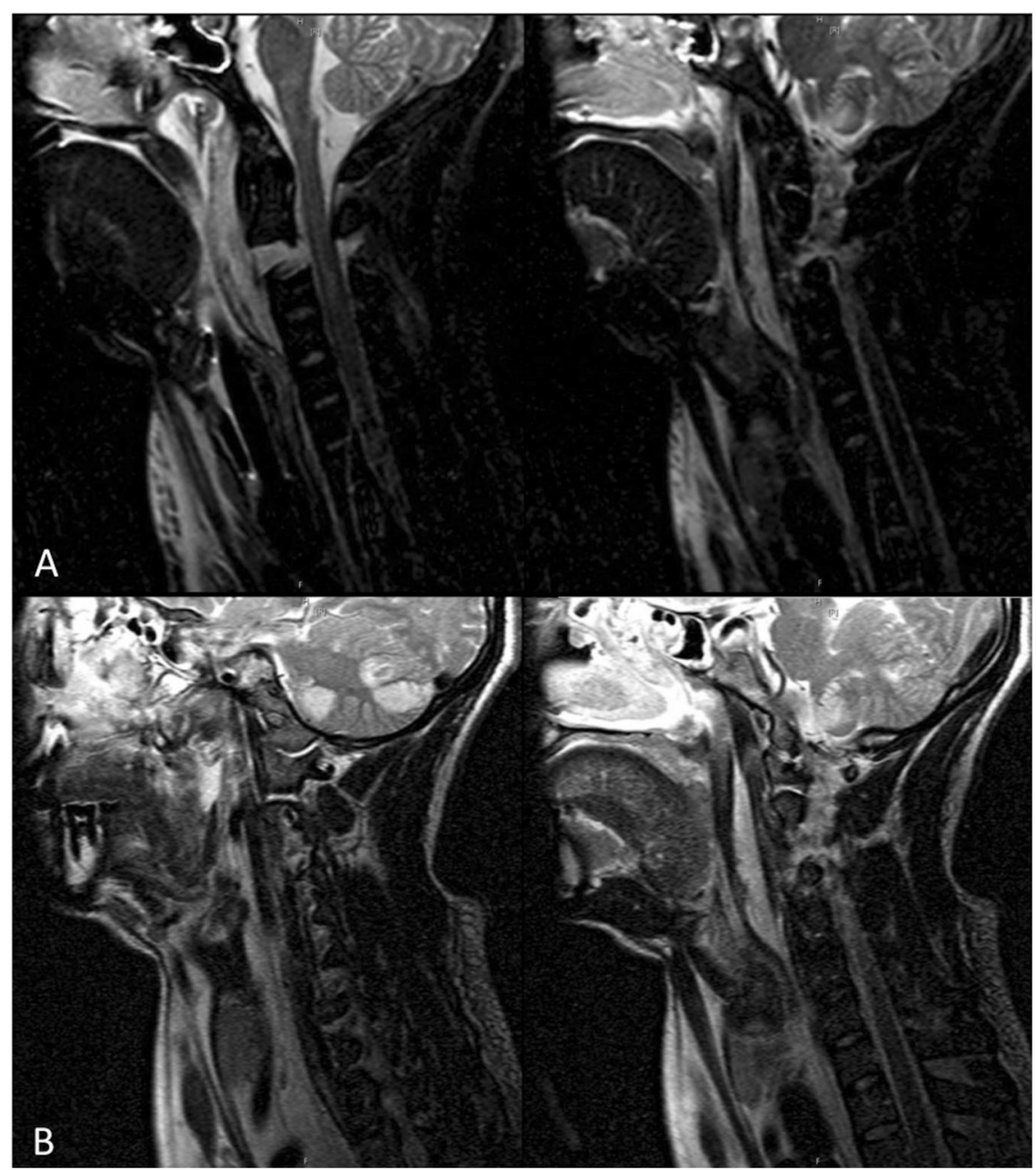

Over the next day, the patient underwent external fixation of his left femur fracture to help with his hemodynamic instability, further delaying obtaining an MRI. Once stable from hemodynamic standpoint, an MRI of the cervical spine (Fig. 3) was performed and revealed a highly unstable cervical spine injury fracture subluxation at the level of 


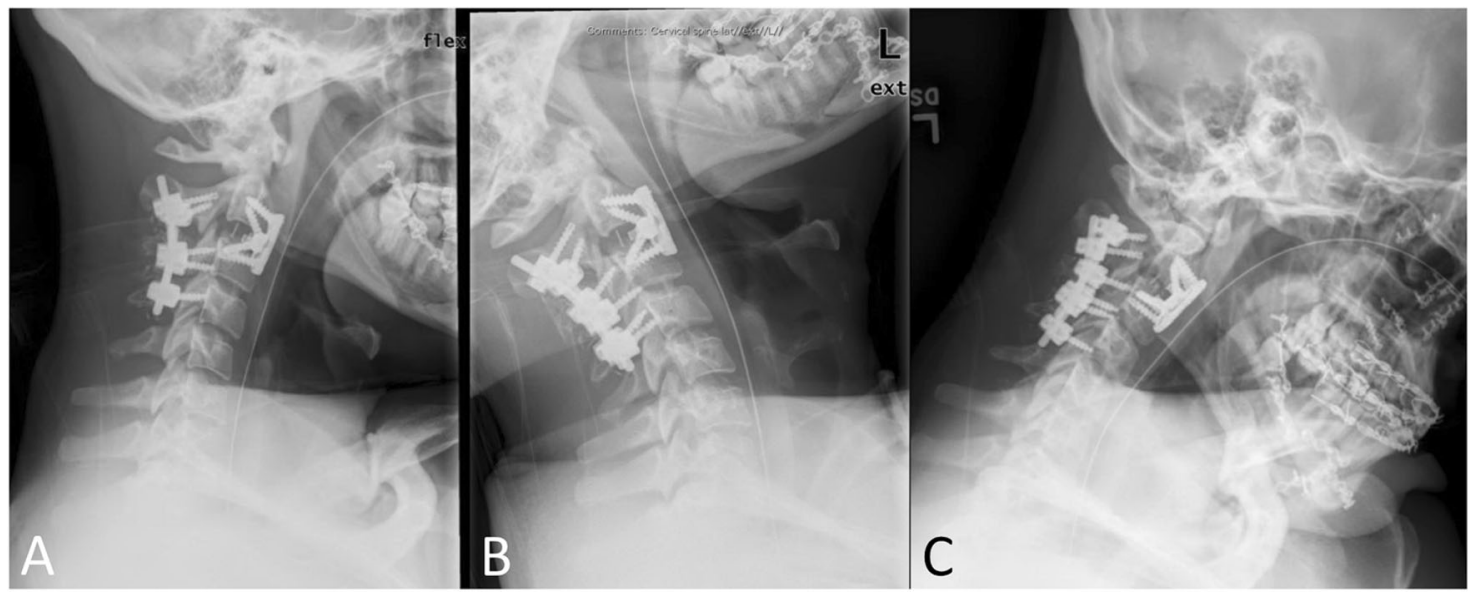

Fig. 4 Cervical spine $\mathrm{x}$-ray at 3 weeks post-op in a neutral position, $\mathbf{b}$ flexion, $\mathbf{c}$ extension with no evidence of instability on flexion or extension

C2-3 with rupture of the anterior longitudinal ligament (ALL), posterior longitudinal ligament (PLL), interspinous ligaments (IS), and associated cord edema at C3, essentially noting complete dissociation of the spinal column at C2-C3. His SLIC score was 9 (3 points for distraction injury, 2 points for disrupted discoligamentous complex, 3 points for incomplete spinal cord injury and 1 additional point for persistent cord compression). An emergent open anterior $\mathrm{C} 2-3$ reduction and discectomy with fusion and plating was performed. The $\mathrm{C} 2-\mathrm{C} 3$ joint was reduced intraoperatively under fluoroscopic $\mathrm{X}$-ray guidance and was stabilized in what appeared to be a neutral position. The following ligamentous disruptions were noted intraoperatively: All injury at C2-3 and bilateral detachment of longus coli and a tear in the PLL. At the end of the case, there was satisfactory stabilization and alignment of the anterior cervical spine. Post-operatively, his neurologic function remained unchanged with minimal movement in bilateral upper extremities.

Despite the anterior fixation, a C2-C3, C3-C4 posterior spinal instrumented fusion was performed the subsequent day due to extent of ligamentous injury. The patient was placed prone in 3-point head fixation pins in neutral position. C2 pars screws, C3 and C4 lateral mass screws were placed with fluoroscopic X-ray guidance. Intraoperatively, C2-3 facets were clearly disrupted bilaterally and complete laceration of the IS and ligamentum flavum was evident. On post-operative day seven the patient began to gradually regained function of his bilateral upper extremities, with significant improvement in the right upper extremity compared to left. He worked extensively with physical therapy and continued to regain function in his upper extremities throughout the hospital course. A cervical spine $\mathrm{x}$-ray performed 3 weeks postoperatively did not show any evidence of instability with flexion or extension (Fig. 4).
Patient was discharged to an acute rehabilitation facility and at his three-month outpatient follow-up, his strength had increased to a $4+/ 5$ in the right upper extremity and antigravity strength in the proximal left upper extremity. Weakness persisted in grip strength and intrinsic hand muscles of the left upper extremity. He was ambulatory and bilateral lower extremities demonstrated full range of motion against gravity and resistance. His bowel and bladder function remained intact. Electromyography studies showed that there was significant peripheral nerve damage in the left upper extremity consistent with a $\mathrm{C} 7$ and $\mathrm{C} 8$ root avulsion. He subsequently underwent successful nerve transfer for his peripheral nerve injury.

A follow-up CT of the C-spine (Fig. 5) obtained 6 weeks after cervical surgery demonstrated stability and intact instrumentation.

\section{Discussion}

Subaxial cervical spine injuries often result in severe debility due to concomitant injury to the spinal cord. To date, there is no unifying algorithm to guide treatment decisions due to extensive variations in pathology and subsequent limitations in generalizability of current literature. Our patient highlights these unique challenges. The patient's injuries had several components, including fracture subluxation, ligamentous disruption, central cord syndrome, and vascular insult. Moreover, the mechanism of our patient's trauma resulted in multiple other injuries, including a hemothorax and fractured femur that deemed him hemodynamically unstable and thus delaying diagnosis and treatment of the suspected SCI. We will address each of these components in detail and review existing case studies to explore the management of subaxial cervical spine injuries. 


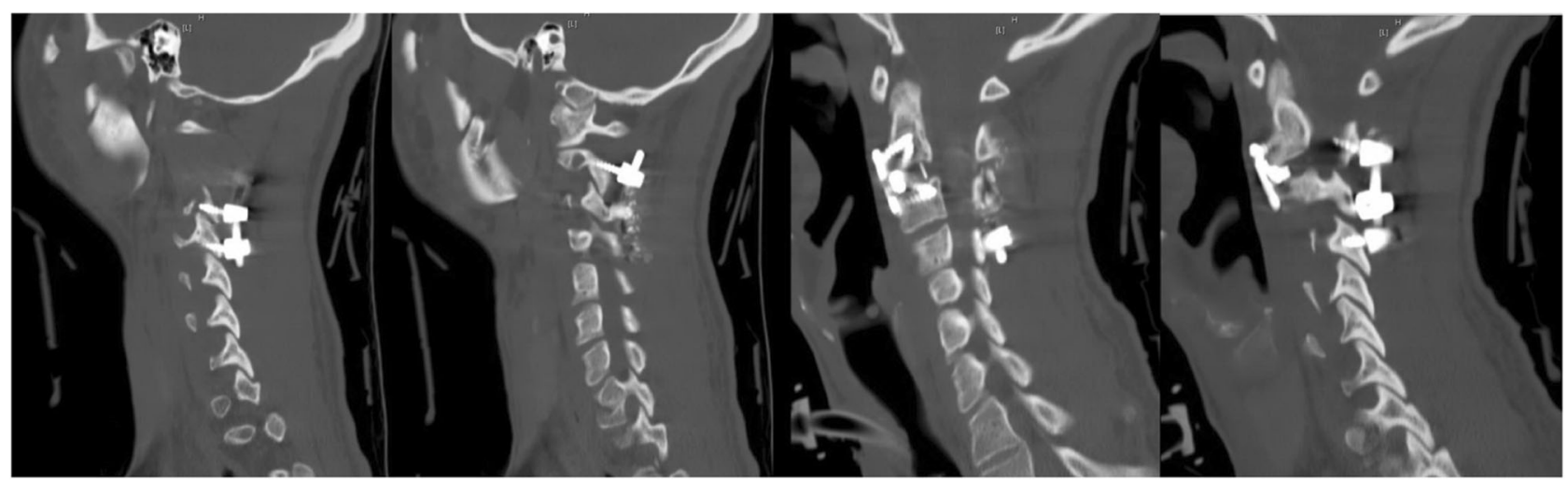

Fig. 5 Sagittal cuts of CT of the cervical spine at 6 weeks post-op showing stability and intact instrumentation

Our patient presented with a fracture subluxation at $\mathrm{C} 2-3$ after being pinned between two trucks. The suspected mechanism of injury was the application of a force vector in the rostral-dorsal direction to the face, resulting in ligamentous disruptions starting from the ALL and progressing posteriorly (PLL, ligamentum flavum, interspinous ligament). As the ALL ruptured at its point of attachment to $\mathrm{C} 2$, avulsion of the anterior inferior segment of $\mathrm{C} 2$ occurred. An additional flexion distraction force explains the bilateral facet dislocations [4]. Disruption of the discoligamentous complex is often associated with a concomitant spinal cord lesion. There is a positive correlation between the number of disrupted ligaments, particularly disruption of the ligamentum flavum, and the length of the spinal cord lesion [9]. Our patient with complete laceration of the IS, ligamentum flavum, ALL and a tear in the PLL was expected to have a large spinal cord lesion. As expected in hyperextension injuries, he developed central cord syndrome likely due to compression of the spinal cord between the vertebral body anteriorly and the buckled ligamentum flavum posteriorly. Imaging displayed no jumped or locked facets, but the degree of soft tissue injury and increased space between the facets on imaging makes us suspect a flexion distraction force $\mathrm{He}$ experienced disproportionate loss of motor function in upper extremities compared to lower extremities and his neurologic function declined progressively [10-12]. Although the length of the spinal cord lesion does not necessarily indicate poor neurologic outcomes, surgical intervention was deemed critical to stabilize the joint and prevent secondary insults.

A serious vascular complication of upper cervical spine fractures with associated vertebral body subluxations is injury to the vertebral artery. Hyperextension with resulting injury to the face or head is the one of the most common mechanisms of injury. Vessel injury can lead to occlusion or distal embolization to the cerebral circulation leading to devastating posterior circulation strokes. Our patient presented with a dissection of the right vertebral artery and occlusion of the left posterior inferior cerebellar arteries resulting in an infarction of the cerebellum. We considered endovascular occlusion of the dissected right vertebral artery to eliminate the source of emboli. However, this option was not pursued due to concerns about a potential brain stem infarction if the basilar artery did not receive adequate flow through the posterior communicating arteries. Thus, he was started on anti-platelet therapy with Aspirin $325 \mathrm{mg}$. Studies have demonstrated similar efficacy between anti-platelet agents and anticoagulants in the treatment of vertebral artery dissections. Although hemorrhagic complications have been reported, the association between these complications and antithrombotic use is not proven [13-15].

Despite our patient's extensive mechanical, neurologic and vascular injuries, it was felt that functional recovery was still possible with early intervention. While early surgery has been shown to improve both neurologic and medical outcomes, there is no consensus on the best timing for surgery after SCI. Additionally, the definition of early surgery varies widely across studies and ranges from eight to seventy-two hours [16-22]. With regards to the specific type of surgery, current guidelines from the American Association of Neurological Surgeons and the Congress of Neurological Surgeons recommend using either an anterior or posterior fixation and fusion. The report concluded that neither approach is superior provided that adequate decompression of the spinal cord is accomplished [23].

There are numerous studies in existing literature presenting the case for anterior, posterior and combined approaches. There is significant variability in surgical approach depending on the extent of injury and surgeon experience although some general trends have been noted. In incomplete SCI, the most common approach (in order of decreasing frequency) is anterior only, posterior only and combined anterior-posterior. In the presence of a traumatic 


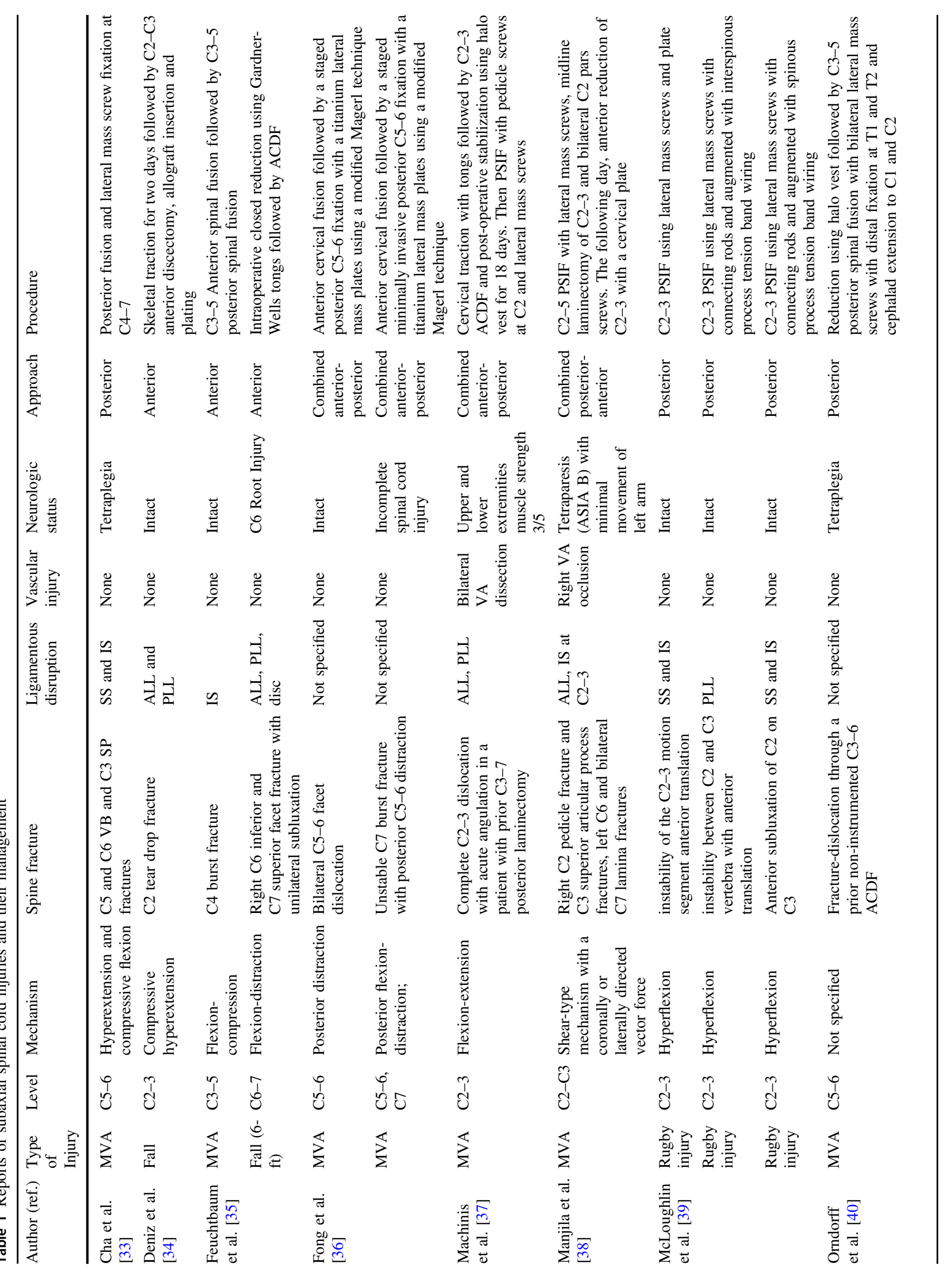


disc herniation, an anterior or combined approach was frequently used [24]. Unstable posterior cervical lateral mass, facet, and ligamentous injuries involving a single level are best treated with an anterior cervical discectomy and fusion. An anterior approach is particularly practical in polytrauma patients where placement in a prone position is not always feasible [25, 26]. Posterior stabilization is frequently used to supplement anterior constructs in cases of multi-column instability or when excessive load on the anterior construct is anticipated [27]. Our literature search of case reports on traumatic subaxial SCIs showed some trends as well. Five out of six studies with C2-3 injury utilized a combined or posterior only approach despite the variation in injury patterns. C5-6 injuries were primarily treated using a combined approach (five out of seven studies) (Table 1). With our patient, we started with an anterior approach. There was the option of performing the posterior fusion during the same time as the anterior, but it was felt that the patient may have adequate stabilization with just an anterior reduction and instrumented fusion. After a postoperative CT scan was reviewed, there was still a widened gap between the $\mathrm{C} 2-\mathrm{C} 3$ facets which was considered worrisome given the amount of injury to the supporting soft tissue structures. It was determined that the patient would benefit from further instrumented stabilization posteriorly. We, therefore proceeded with a posterior fusion. Given the extensive ligamentous injuries posteriorly, we felt that an extended fusion below the level of the injury to $\mathrm{C} 4$ would provide better stabilization without restricting range of motion, explaining why the fusion was not extended above the level of injury to $\mathrm{C} 1$. Anchoring the top of the construct with $\mathrm{C} 2$ pars screws provides a robust point of fixation especially in comparison to lateral mass screws. More importantly, the ligamentous complex between occiput to $\mathrm{C} 2$ remained uninjured conveying occipito-cervical stability.

Our patient had significant improvement in neurologic function throughout his hospital course and subsequently in rehabilitation. At his most recent rehabilitation visit, six months after injury, he was able to walk independently without any assistive devices for at least 15 -feet. His bowel and bladder function remained intact. This corroborates evidence from existing literature that patients with central cord syndrome, despite presenting with low motor and selfcare functional independence measures, demonstrate significant improvements in both motor and self-care ability after discharge [11, 28-32]. Furthermore, during the rehabilitation course, our patient was found to have peripheral nerve injury from root avulsion which went unnoticed during his hospital admission but likely contributed to his neurologic deficits. This is an entity can be overlooked in patients with polytrauma whose physical exam do not correspond to findings on central nervous system imaging. 
Overall, the case we presented brings together multiple areas of consideration in a patient with spinal cord instability and injury following a devastating trauma. In addition, it provides an example of a relatively uncommon injury pattern with complete dissociation of the subaxial spine and one method of management. We also present cases in literature of subaxial spinal injury and their approach to management. At present, algorithmic management of subaxial spinal injury is mainly driven by the SLIC grading system, however specific operative approaches are still mainly driven by surgeon preference.

\section{Compliance with ethical standards}

Conflict of interest The authors declare that they have no conflict of interest.

Publisher's note: Springer Nature remains neutral with regard to jurisdictional claims in published maps and institutional affiliations.

\section{References}

1. Albin M. Acute spinal cord trauma. In: Shoemaker W, Thompson W, Holbrook P, eds. Critical care. Philadelphia: W. B. Saunders; 928-32.

2. National Spinal Cord Injury Statistical Center. Spinal cord injury facts and figures at a glance. Birmingham: National Spinal Cord Injury Statistical Center, University of Alabama at Birmingham; 2013.

3. Desouza RM, Crocker MJ, Haliasos N, Rennie A, Saxena A. Blunt traumatic vertebral artery injury: a clinical review. Eur Spine J. 2011;20:1405-16.

4. Moore NZ, Sultan AA, Benzel EC. Biomechanics of the spine. In: Jallo A, Vaccaro AR. Neurotrauma and critical care of the spine. 2nd ed. New York: Thieme; 2018.

5. Aarabi B, Walters BC, Dhall SS, Gelb DE, Hurlbert RJ, Rozzelle CJ, et al. Subaxial cervical spine injury classification systems. Neurosurgery. 2013;72:170-86.

6. Joaquim AF, Lawrence B, Daubs M, Brodke D, Patel AA. Evaluation of the subaxial injury classification system. J Craniovertebr Junction Spine. 2011;2:67-72.

7. Patel AA, Dailey A, Brodke DS, et al. Subaxial cervical spine trauma classification: the subaxial injury classification system and case examples. Neurosurg Focus. 2008;25:E8.

8. Raniga SB, Menon V, Al Muzahmi KS, Butt S. MDCT of acute subaxial cervical spine trauma: a mechanism-based approach. Insights Imaging. 2014;5:321-38.

9. Martinez-Perez R, Paredes I, Cepeda S, et al. Spinal cord injury after blunt cervical spine trauma: correlation of soft-tissue damage and extension of lesion. Am J Neuroradiol. 2014;35:1029-34.

10. Aarabi B, Koltz M, Ibrahimi D. Hyperextension cervical spine injuries and traumatic central cord syndrome. Neurosurg Focus. 2008;25:E9.

11. McKinley W, Santos K, Meade M, Brooke K. Incidence and outcomes of spinal cord injury clinical syndromes. J Spinal Cord Med. 2007;30:215-24.

12. Torretti JA, Sengupta DK. Cervical spine trauma. Indian J Orthop. 2007;41:255-67.

13. CADISS trial investigators, Markus HS, Hayter E, et al. Antiplatelet treatment compared with anticoagulation treatment for cervical artery dissection (CADISS): a randomised trial. Lancet Neurol. 2015;14:361-7.

14. Kennedy F, Lanfranconi S, Hicks C, et al. Antiplatelets vs. anticoagulation for dissection: CADISS nonrandomized arm and meta-analysis. Neurology. 2012;79:686-9.

15. Daou B, Hammer C, Mouchtouris N, et al. Anticoagulation vs. antiplatelet treatment in patients with carotid and vertebral artery dissection: a study of 370 patients and literature review. Neurosurgery. 2017;80:368-79.

16. Rath N, Balain B. Spinal cord injury-the role of surgical treatment for neurological improvement. J Clin Orthop Trauma. 2017;8:99-102.

17. Mirza SK, Krengel WF 3rd, Chapman JR, et al. Early versus delayed surgery for acute cervical spinal cord injury. Clin Orthop Relat Res. 1999;359:104-14.

18. Fehlings MG, Perrin RG. The timing of surgical intervention in the treatment of spinal cord injury: a systematic review of recent clinical evidence. Spine. 2006;31:S28-35.

19. Liu Y, Shi CG, Wang XW, et al. Timing of surgical decompression for traumatic cervical spinal cord injury. Int Orthop. 2015;39:2457-63.

20. Papadopoulos SM, Selden NR, Quint DJ, Patel N, Gillespie B, Grube S. Immediate spinal cord decompression for cervical spinal cord injury: feasibility and outcome. J Trauma. 2002;52:323-32.

21. Lubelski D, Tharin S, Como JJ, Steinmetz MP, Vallier H, Moore T. Surgical timing for cervical and upper thoracic injuries in patients with polytrauma. J Neurosurg Spine. 2017;27:633-7.

22. Jug M, Kejzar N, Vesel M, et al. Neurological recovery after traumatic cervical spinal cord injury is superior if surgical decompression and instrumented fusion are performed within $8 \mathrm{~h}$ versus 8 to $24 \mathrm{~h}$ after injury: a single center experience. J Neurotrauma. 2015;32:1385-92.

23. Gelb DE, Aarabi B, Dhall SS, Hurlbert RJ, Rozzelle CJ, Ryken TC, et al. Treatment of subaxial cervical spinal injuries. Neurosurgery. 2013;72:187-94.

24. Nassr A, Lee JY, Dvorak MF, et al. Variations in surgical treatment of cervical facet dislocations. Spine. 2008;33:E188-93.

25. Razack N, Green BA, Levi AD. The management of traumatic cervical bilateral facet fracture-dislocations with unicortical anterior plates. J Spinal Disord. 2000;13:374-81.

26. Woodworth RS, Molinari WJ, Brandenstein D, Gruhn W, Molinari RW. Anterior cervical discectomy and fusion with structural allograft and plates for the treatment of unstable posterior cervical spine injuries. J Neurosurg Spine. 2009;10:93-101.

27. Liu JK, Das K. Posterior fusion of the subaxial cervical spine: Indications and techniques. Neurosurg Focus. 2001;10:E7.

28. Aito S, D'Andrea M, Werhagen L, et al. Neurological and functional outcome in traumatic central cord syndrome. Spinal Cord. 2007;45:292-7.

29. Newey ML, Sen PK, Fraser RD. The long-term outcome after central cord syndrome: a study of the natural history. J Bone $\mathrm{Jt}$ Surg Br. 2000;82:851-5.

30. Roth EJ, Lawler MH, Yarkony GM. Traumatic central cord syndrome: clinical features and functional outcomes. Arch Phys Med Rehabil. 1990;71:18-23.

31. Dvorak MF, Fisher CG, Hoekema J, et al. Factors predicting motor recovery and functional outcome after traumatic central cord syndrome: a long-term follow-up. Spine. 2005;30:2303-11.

32. Pollard ME, Apple DF. Factors associated with improved neurologic outcomes in patients with incomplete tetraplegia. Spine. 2003;28:33-39.

33. Cha YH, Cho TH, Suh JK. Traumatic cervical cord transection without facet dislocations--a proposal of combined hyperflexionhyperextension mechanism: a case report. J Korean Med Sci. 2010;25:1247-50. 
34. Deniz FE, Cagli S, Zileli M. Compressive hyperextension injury of C2-C3 managed with anterior plate fixation: case report. Turk Neurosurg. 2007;17:125-8.

35. Feuchtbaum E, Buchowski J, Zebala L. Subaxial cervical spine trauma. Curr Rev Musculoskelet Med. 2016;9:496-504.

36. Fong S, Duplessis S. Minimally invasive lateral mass plating in the treatment of posterior cervical trauma: surgical technique. J Spinal Disord Tech. 2005;18:224-8.

37. Machinis TG, Fountas KN, Kapsalaki EZ, Kapsalakis I, Grigorian AA. A rare case of complete C2-C3 dislocation with mild neurological symptoms. Eur Spine J. 2006;15:585-9.

38. Manjila S, Chowdhry SA, Bambakidis NC, Hart DJ. Traumatic, high-cervical, coronal-plane spondyloptosis with unilateral vertebral artery occlusion: treatment using a prophylactic arterial bypass graft, open reduction, and instrumented segmental fusion. J Neurosurg Spine. 2014;20:183-90.

39. McLoughlin LC, Jadaan M, McCabe J. Severe sprains of the subaxial cervical spine in adolescents: a diagnostic and therapeutic challenge: a report of three cases. Eur Spine J. 2014;23:150-6.
40. Orndorff DG, Samartzis D, Whitehill R, Shen FH. Traumatic fracture-dislocation of C5 on C6 through a previously solid multilevel anterior cervical discectomy and fusion: a case report and review of the literature. Spine J. 2006;6:55-60.

41. Payer M, Tessitore E. Delayed surgical management of a traumatic bilateral cervical facet dislocation by an anterior-posterioranterior approach. J Clin Neurosci. 2007;14:782-6.

42. Shimada T, Ohtori S, Inoue G, et al. Delayed surgical treatment for a traumatic bilateral cervical facet joint dislocation using a posterior-anterior approach: a case report. J Med Case Rep. 2013;7:9-1947-7-9.

43. Zhou Y, Zhou Z, Liu L, Cao X. Management of irreducible unilateral facet joint dislocations in subaxial cervical spine: two case reports and a review of the literature. J Med Case Rep. 2018;12:74-018-1609-z. 